\title{
Trimethylamine Oxide: A Terminal Electron Acceptor in Anaerobic Respiration of Bacteria
}

\author{
By ARNE R. STR ØM,* JAN A. OLAFSEN* AND HELGE LARSEN \\ Department of Biochemistry, Norwegian Institute of Technology, \\ University of Trondheim, Trondheim, Norway
}

(Received 17 November 1978)

\begin{abstract}
Trimethylamine oxide (TMAO) stimulated both the anaerobic growth rate and the growth yield of Proteus NTHC 153. The molar growth yield from glucose and pyruvate in tryptone/ yeast extract medium doubled in the presence of TMAO, and the organism grew anaerobically on the non-fermentable substrates L-lactate and formate when TMAO was added to the medium. We conclude that TMAO stimulated growth by serving as a terminal electron acceptor in an oxidative phosphorylation process.
\end{abstract}

\section{INTRODUCTION}

Trimethylamine oxide (TMAO) is a constituent of marine animals, including both fish and invertebrates (Groninger, 1959; Yamada, 1967). Post mortem, TMAO is reduced by bacteria, notably Gram-negative rods, to trimethylamine (TMA) which gives rise to the characteristic off-flavour of marine fish in the early stage of decay (Beatty \& Gibbons, 1937; Tarr, 1954). The bacteria can use a variety of hydrogen donors for TMAO reduction according to the general equation (Watson, 1939a, $b$; Unemoto et al., 1964):

$$
\left(\mathrm{CH}_{3}\right)_{3} \mathrm{NO}+\mathrm{AH}_{2} \longrightarrow\left(\mathrm{CH}_{3}\right)_{3} \mathrm{~N}+\mathrm{A}+\mathrm{H}_{2} \mathrm{O}
$$

We have previously reported that TMAO stimulates the anaerobic growth of bacteria in fish muscle extracts (Strøm, 1971). Promotion of anaerobic growth of bacteria by TMAO has also been reported for Salmonella typhimurium (Kim \& Chang, 1974), Escherichia coli (Yamamoto \& Ishimoto, 1977) and Rhodopseudomonas capsulata (Madigan \& Gest, 1978). We have now determined the growth yields of Proteus NTHC 153 under various conditions to determine whether TMAO can serve as electron acceptor for redox reactions coupled to energy conservation: if so, this would be a new example of the general phenomenon of anaerobic respiration.

\section{METHODS}

Organism and growth. Proteus NTHC 153 was isolated from an enrichment culture made by inoculating a small piece of herring gill into a sterile extract of herring muscle and incubating at $15^{\circ} \mathrm{C}$ under anaerobic conditions until maximum bacterial growth was reached (Strøm, 1971; Strøm \& Larsen, 1979). It was grown anaerobically at $25^{\circ} \mathrm{C}$ in glass-stoppered culture tubes which were completely filled. The media contained ( $\mathrm{g} \mathrm{l}^{-1}$ in tap water): $\mathrm{KH}_{2} \mathrm{PO}_{4}, 1 \cdot 2 ; \mathrm{NH}_{4} \mathrm{Cl}, 0.8 ; \mathrm{MgSO}_{4} .7 \mathrm{H}_{2} \mathrm{O}, 0.08 ; \mathrm{NaCl}, 2 \cdot 4$; tryptone (Difco), 1.6; yeast extract (Oxoid), 0.4; Tris, 5.6. When used, TMAO was added to give $50 \mathrm{~mm}$. Solutions of D-glucose, sodium lactate, sodium pyruvate and sodium formate were sterilized by filtration and added to give the concentrations specified in the text. The $\mathrm{pH}$ was adjusted to $7 \cdot 1$ and $7 \cdot 6$ for media with and without TMAO, respectively. The media were inoculated with $2 \%(\mathrm{v} / \mathrm{v})$ of a culture actively growing in the same medium.

* Present address: Institute of Fisheries, University of Tromsø, Troms $ø$, Norway. 

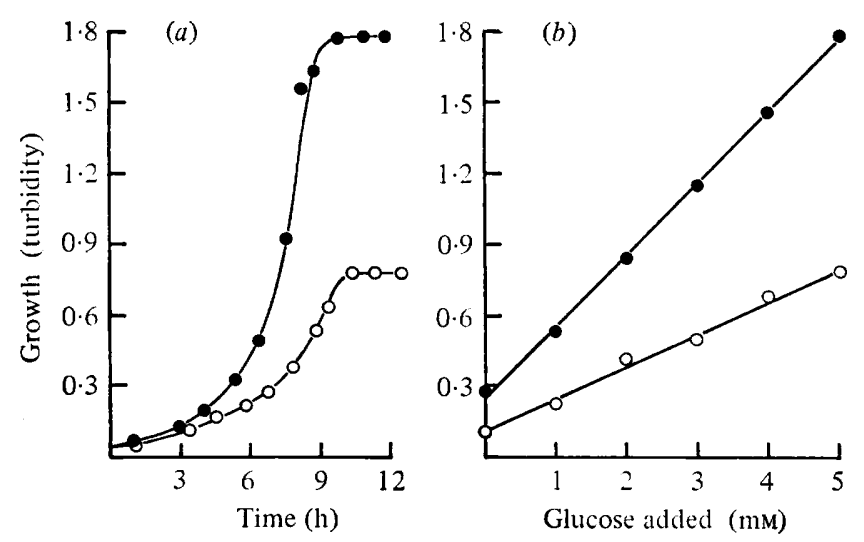

Fig. 1. Effect of TMAO on anaerobic growth of Proteus NTHC 153. The organism was grown at $25^{\circ} \mathrm{C}$ in glucose/tryptone/yeast extract medium in the presence $(O)$ or absence $(O)$ of $50 \mathrm{~mm}$ TMAO. (a) Growth with glucose at an initial concentration of $5 \mathrm{mM}$. (b) Maximum density with different initial concentrations of glucose.

Determination of glucose assimilation. To the above medium containing 5 mm-glucose, with or without TMAO, D-[U-14 C]glucose (194 $\mathrm{mCi} \mathrm{mmol}^{-1}$; The Radiochemical Centre, Amersham) was added to give $0.13 \mu \mathrm{M}$. The media, completely filling the glass-stoppered culture tubes, were inoculated with the organism and incubated at $25^{\circ} \mathrm{C}$. Soon after growth had ceased, bacteria were harvested by centrifuging (10000 $\mathrm{g}$ for $10 \mathrm{~min}, 4^{\circ} \mathrm{C}$ ), washed once with water and treated with formamide (Neujahr \& Ewaldson, 1964). Scintillation liquid (Bray, 1960) was added, and the solution was counted in a Packard model 3375 Tri-Carb liquid scintillation spectrometer. Counts per minute were converted to disintegrations per minute by the channels ratio method.

Determination of growth yield. Growth was measured in an EEL portable colorimeter with filter no. 626. Dry weight was determined by transferring washed bacteria, resuspended in water, to a membrane filter (Sartorius SM11305) and drying at $105^{\circ} \mathrm{C}$. Cell nitrogen was determined by the Kjeldahl method.

Chemical analyses. Glucose, pyruvate and formate were assayed by colorimetric methods according to Bartlett (1959), Friedemann (1957) and Wood \& Gest (1957), respectively. L-Lactate was determined by an enzymic method (Hohorst, 1962). Acetate was measured with a Varian Aerograph model 204 gas chromatograph equipped with a flame ionization detector and a $1.5 \mathrm{~m} \times 3.2 \mathrm{~mm}$ (o.d.) stainless steel column filled with $10 \%(w / w)$ neopentyl glycol succinate plus $2 \%(w / w) \mathrm{H}_{3} \mathrm{PO}_{4}$ on Firebrick, 60 to 80 mesh (Varian Aerograph). TMAO and TMA were determined by the microdiffusion technique (Conway \& Byrne, 1933) and $\mathrm{CO}_{2}$ by van Slyke's manometric method (N. N., 1956).

\section{RESULTS}

\section{Growth on glucose}

Proteus NTHC 153 grew more rapidly and to twice the final cell density in the presence of TMAO than in its absence (Fig. 1a). During exponential growth the generation time was $1.5 \mathrm{~h}$ in the medium containing TMAO, compared with $2.2 \mathrm{~h}$ in its absence. Estimations of dry weight and cell nitrogen indicated that growth was increased in the presence of TMAO by 84 and $87 \%$, respectively. These results support the contention that TMAO stimulated normal growth rather than the accumulation of metabolites such as reserve material.

In unsupplemented cultures, the $\mathrm{pH}$ decreased during growth, but in the presence of TMAO the $\mathrm{pH}$ increased due to the formation of TMA. In order to counteract the opposite $\mathrm{pH}$ changes the media were well buffered, and a lower initial $\mathrm{pH}$ was chosen for the cultures supplemented with TMAO $(7 \cdot 1$ instead of $7 \cdot 6)$. The $\mathrm{pH}$ values in fully grown cultures were 7.5 and $6 \cdot 8$, respectively. Since Proteus species grow profusely over a considerably wider $\mathrm{pH}$ range than this, it is unlikely that the stimulation of growth by TMAO was due to a $\mathrm{pH}$ effect. 
Table 1. Quantitative characteristics of the anaerobic growth of Proteus NTHC 153 on various substrates in complex medium with or without trimethylamine oxide

\begin{tabular}{|c|c|c|c|c|c|c|}
\hline \multirow{2}{*}{$\begin{array}{c}\text { Substrate and } \\
\text { hydrogen acceptor }\end{array}$} & \multirow{2}{*}{$\begin{array}{l}\text { Molar growth } \\
\text { yield [ } \mu \mathrm{g} \text { dry } \\
\text { wt }(\mu \mathrm{mol} \\
\left.\text { substrate })^{-1}\right]\end{array}$} & \multicolumn{3}{|c|}{ Products $\left[\mu \mathrm{mol}(\mu \mathrm{mol} \text { substrate })^{-1}\right]$} & \multirow{2}{*}{$\begin{array}{c}\text { ATP formation } \\
\text { at substrate } \\
\text { level }[\mu \mathrm{mol} \\
\left.(\mu \text { mol substrate })^{-1}\right]\end{array}$} & \multirow{2}{*}{$\begin{array}{c}Y_{\mathrm{ATP}} \\
{[\mu \mathrm{g} \text { dry wt }} \\
\left.(\mu \mathrm{mol} \mathrm{ATP})^{-1}\right]\end{array}$} \\
\hline & & TMA & $\mathrm{CO}_{2}$ & Acetate & & \\
\hline Glucose & $38 \cdot 5$ & 0 & $\cdot$ & 0.97 & $2+0.97=2.97$ & $13 \cdot 0$ \\
\hline Glucose + TMAO & $77 \cdot 0$ & $3 \cdot 50$ & $\cdot$ & $1 \cdot 76$ & $2+1 \cdot 76=3 \cdot 76$ & - \\
\hline Pyruvate & $5 \cdot 9$ & 0 & $0 \cdot 38$ & 0.76 & $0 \cdot 76$ & $7 \cdot 8$ \\
\hline Pyruvate + TMAO & $14 \cdot 7$ & 0.94 & 0.89 & $0 \cdot 75$ & $0 \cdot 75$ & - \\
\hline L-Lactate + TMAO & $13 \cdot 0$ & 1.82 & 0.83 & $0 \cdot 77$ & $0 \cdot 77$ & - \\
\hline Formate + TMAO & $10 \cdot 3$ & 1.06 & 0.97 & 0 & 0 & - \\
\hline
\end{tabular}

Complex media can provide many of the biosynthetic precursors required for bacterial growth and glucose is therefore used predominantly as an energy source. This was demonstrated in experiments with $\left[\mathrm{U}-{ }^{14} \mathrm{C}\right] \mathrm{glucose}$ in which it was established that 17 and $7 \%$, respectively, of added glucose was assimilated by the bacteria in media with and without TMAO; the rest ( 83 and $93 \%$, respectively) was presumably utilized in the dissimilation process.

Growth was glucose-limited up to at least $5 \mathrm{~mm}$ (Fig. $1 \mathrm{~b}$ ) and with this initial concentration only $40 \%$ of the TMAO had been reduced by the fully grown cultures. A small amount of growth occurred in the absence of glucose, presumably because nutrients in the complex medium served as energy sources (Fig. $1 b$ ).

For molar growth yield determinations (Table 1), glucose was used at an initial concentration of $5 \mathrm{~mm}$. Corrections have been made for the 'background' growth in the absence of glucose and for the glucose assimilated. The former correction was based on the determination of turbidity in cultures with and without glucose (Fig. 1b). The molar growth yield from glucose doubled in the presence of TMAO. The quantities of acetate and TMA produced (Table 1) have been corrected for the amounts of products formed in the absence of added glucose. More acetate accumulated when TMAO was added to the glucose medium.

Enterobacteria ferment glucose by the glycolytic pathway in which two molecules of ATP are formed per molecule of glucose dissimilated to pyruvate (Wood, 1961). A further molecule of ATP is formed when acetate is generated from acetyl phosphate. For Proteus NTHC 153 the $Y_{\text {ATP }}$ value, defined by Bauchop \& Elsden (1960), was 13.0 during anaerobic growth with glucose (Table 1). Similar values have been found by other investigators for other strains of enterobacteria grown in similar media (Stouthamer, 1969, 1977; Forrest \& Walker, 1971).

\section{Growth on formate, lactate and pyruvate}

To obtain more information about the bacterial reduction of TMAO, Proteus NTHC 153 was grown in anaerobic tryptone/yeast extract medium with excess of TMAO (50 mM) and various amounts of the non-fermentable substrates L-lactate and formate. For comparison, the anaerobic growth on pyruvate, with or without TMAO, was also measured. Pyruvate and L-lactate were growth-limiting at $20 \mathrm{~mm}$ (Fig. 2). When formate was the substrate, there was an approximately linear relationship between the final density of the culture and the initial concentration of formate up to about $10 \mathrm{mM}$. The organism could not utilize formate or L-lactate as a substrate for anaerobic growth in media without TMAO; D-lactate did not support anaerobic growth even in media containing TMAO.

In the determinations of the molar growth yields (Table 1), lactate and pyruvate were used at an initial concentration of $20 \mathrm{~mm}$ and formate at $10 \mathrm{~mm}$. The actual amounts of substrate converted by the bacteria were determined but not the amounts of substrate assimilated. All results have been corrected for 'background growth' and dissimilation 


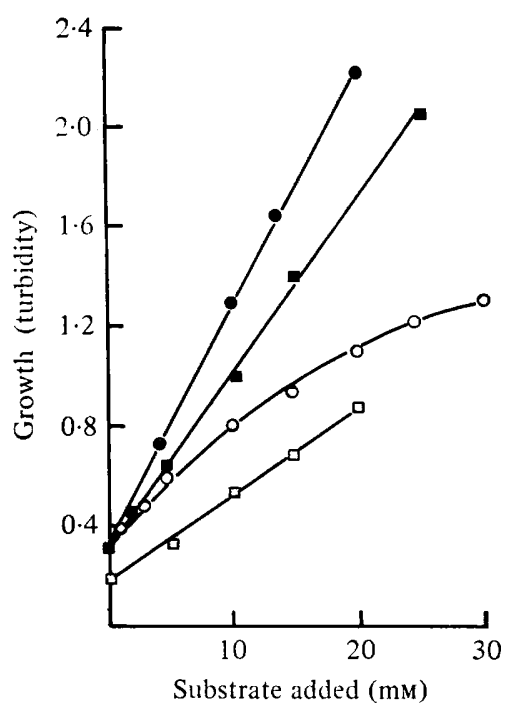

Fig. 2. Maximum density of Proteus NTHC 153 grown at $25^{\circ} \mathrm{C}$ in tryptone/yeast extract basal medium containing: $\square$, pyruvate; $\mathbf{\square}$, pyruvate plus TMAO; $\bigcirc$, formate plus TMAO; $\bigcirc, \mathrm{L}-$ lactate plus TMAO. The initial concentration of TMAO was $50 \mathrm{mM}$.

products (acetate, $\mathrm{CO}_{2}$ and TMA) formed in the absence of added substrate. The molar growth yield from pyruvate more than doubled in the presence of TMAO and was about the same as the molar growth yield from L-lactate in the presence of TMAO. From the results for growth on pyruvate in the absence of TMAO, a $Y_{\text {ATP }}$ value of 7.8 was calculated.

The data for the conversion of formate fit the stoicheiometry of the equation:

$$
\left(\mathrm{CH}_{3}\right)_{3} \mathrm{NO}+\mathrm{HCOOH} \longrightarrow\left(\mathrm{CH}_{3}\right)_{3} \mathrm{~N}+\mathrm{CO}_{2}+\mathrm{H}_{2} \mathrm{O}
$$

The molar growth yield from formate was $10 \cdot 3$. A corresponding value of $7 \cdot 0$ has been determined for E. coli (Yamamoto \& Ishimoto, 1977).

\section{Distribution of TMAO respiration among bacterial species}

Seven strains of bacteria were isolated from an anaerobic enrichment culture on fish extract as described for Proteus NTHC 153 (see Methods). The organisms were all Gramnegative rods but differed with respect to the appearance of colonies, size of cells and motility. They were not identified. None grew when inoculated into the glucose/tryptone/ yeast extract medium and incubated anaerobically. However, when TMAO or nitrate was added to the medium, all seven organisms grew well. These observations indicated that the ability to utilize TMAO as terminal electron acceptor during anaerobic growth might be fairly common among bacteria, as is the ability to utilize nitrate.

\section{DISCUSSION}

When enterobacteria metabolize carbohydrate anaerobically, a number of externally added hydrogen acceptors such as nitrate, nitrite, thiosulphate and tetrathionate can stimulate the production of acetate (Forget \& Pichinoty, 1964; Hadjipetrou \& Stouthamer, 1965; Stouthamer \& Bettenhausen, 1972). An increased production of acetate from acetyl phosphate leads to an increased production of ATP, and in this way an externally added hydrogen acceptor may stimulate anaerobic growth (Stouthamer, 1969). However, this 'acetate effect' can account for only a small part of the substantial increase in growth yield 
of Proteus NTHC 153 obtained on adding TMAO to the glucose medium: the increase in estimated production of ATP by substrate-level phosphorylation was $27 \%$, whereas the increase in molar growth yield was $100 \%$ (Table 1). Furthermore, bacterial conversion of formate to $\mathrm{CO}_{2}$ cannot support ATP synthesis by any known mechanism of substrate-level phosphorylation. The only reasonable explanation seems to be that an extra mechanism for the production of ATP has come into operation in which TMAO acts as a terminal electron acceptor in a redox system coupled to ATP production. Evidence for TMAO respiration has also been reported for other strains of enterobacteria (Kim \& Chang, 1974; Yamamoto \& Ishimoto, 1977).

An NALH-dependent TMAO reductase system has been detected in cell-free extracts of Vibrio parahaemolyticus (Unemoto et al., 1965). Formate, NADH and NADPH were effective electron donors for the reduction of TMAO by extracts of $E$. coli (Sakaguchi \& Kawai, 1977), and formate, NADH and D-lactate can be used to reduce nitrate (for review, see Haddock \& Jones, 1977). The redox potential of the TMAO/TMA couple is about $+0.13 \mathrm{~V}$ (Castell, 1950); $E_{0}^{\prime}$ for $\mathrm{CO}_{2} /$ formate is $-0.43 \mathrm{~V}$ (Netter, 1969), that of NAD/ $\mathrm{NADH}$ is $-0.32 \mathrm{~V}$ and that of pyruvate/lactate is $-0.19 \mathrm{~V}$ (Lehninger, 1970). Thus $\Delta G^{\circ}$ for the reduction of TMAO by formate, NADH and lactate will be, respectively, about $-26,-21$ and $-15 \mathrm{kcal} \mathrm{mol}^{-1}\left(-6.2,-5.0\right.$ and $\left.-3.6 \mathrm{~kJ} \mathrm{~mol}^{-1}\right)$. Thermodynamically, it is therefore feasible that the reduction of TMAO by these electron donors can be coupled to oxidative phosphorylation.

The $Y_{\text {ATP }}$ values calculated from our data for growth with glucose and pyruvate were 13.0 and $7 \cdot 8$, respectively (Table 1). Stouthamer (1977) reported that $Y_{\text {ATP }}$ values depend on the growth conditions; this implies that an accurate $\mathrm{P} / 2 \mathrm{e}^{-}$ratio cannot be calculated from our data. However, the molar growth yield from formate $(10 \cdot 3)$ compared with the $Y_{\mathrm{ATP}}$ value determined from growth on the simple substrate pyruvate $(7 \cdot 8)$ indicates that the $\mathrm{P} / 2 \mathrm{e}^{-}$ratio was at least 1 when formate was the electron donor for the reduction of TMAO. We cannot conclude whether electrons liberated from 3-phosphoglyceraldehyde during glucose dissimilation were coupled to oxidative phosphorylation, since the increased growth yield obtained on adding TMAO to glucose media may be due to oxidation of formate formed from glucose. Furthermore, our results indicate that no ATP is formed during the initial step in the oxidation of L-lactate by TMAO because the molar growth yields from L-lactate and pyruvate were similar in the presence of TMAO (Table 1). The initial oxidation of L-lactate is presumably catalysed by an NAD-independent flavoprotein (Kline \& Mahler, 1965). It thus seems probable that Proteus NTHC 153 may also have a TMAO reduction system which is not coupled to translocation of protons and consequent ATP production.

The content of TMAO in various marine animals varies within wide limits, but is often 2 to $4 \%$ of the dry weight of a teleost and 3 to $7 \%$ of the dry weight of an elasmobranch (Groninger, 1959; Yamada, 1967). TMAO is thus one of the most common organic molecules in the marine environment. When a marine animal dies, aerobic bacteria will probably start the decay process but oxygen will soon become a limiting factor. Apparently a number of the bacteria can easily switch from aerobic respiration to anaerobic respiration using the readily available TMAO as an electron acceptor. Such bacteria would have a great advantage over those which can only switch from aerobic respiration to a simple fermentation.

The work was supported by a grant from The Royal Norwegian Council for Scientific and Industrial Research. 


\section{REFERENCES}

BARTLETT, G. R. (1959). Methods for the isolation of glycolytic intermediates by column chromatography with ion exchange resins. Journal of Biological Chemistry 234, 459-465.

BAUCHOP, T. \& ElsDEN, S. R. (1960). The growth of micro-organisms in relation to their energy supply. Journal of General Microbiology 23, 457-469.

Beatty, S. A. \& Gibbons, N. E. (1937). The measurement of spoilage in fish. Journal of the Biological Board of Canada 3, 70-76.

BrAY, G. A. (1960). A simple efficient liquid scintillator for counting aqueous solutions in a liquid scintillation counter. Analytical Biochemistry 1, 279-285.

Castell, C. H. (1950). The influence of trimethylamine oxide on the bacterial reduction of redox indicators. Journal of the Fisheries Research Board of Canada 7, 567-575.

Conway, E. F. \& BYRNE, A. (1933). An absorption apparatus for the micro-determination of certain volatile substances. I. The micro-determination of ammonia. Biochemical Journal 27, 419-429.

Forget, P. \& Pichinoty, F. (1964). Influence de la respiration anaérobie du nitrate et du fumarate sur le métabolisme fermentaire d'Aerobacter aerogenes. Biochimica et biophysica acta 82 , 441-444.

Forrest, W. W. \& Walker, D. J. (1971). The generation and utilization of energy during growth. Advances in Microbial Physiology 5, 213-274.

FRIEDEMANN, T. E. (1957). Determination of $\alpha$-keto acids. Methods in Enzymology 3, 415-418.

GronINGER, H. S. (1959) Occurrence and Significance of Trimethylamine Oxide in Marine Animals, Special Scientific Report - Fisheries no. 333. Washington, D.C.: United States Fish and Wildlife Service.

HaDdock, B. A. \& Jones, C. W. (1977). Bacterial respiration. Bacteriological Reviews 41, 47-99.

Hadjipetrou, L. P. \& Stouthamer, A. H. (1965). Energy production during nitrate respiration by Aerobacter aerogenes. Journal of General Microbiology 38, 29-34.

HoHoRst, H. J. (1962). L-(+)-Lactat Bestimmung mit Lactat-Dehydrogenase und DPN. In Methoden der Enzymatischen Analyse, pp. 266-270. Edited by H. U. Bergmeyer. Weinheim: Verlag Chemie.

KIM, K. E. \& Chang, G. W. (1974). Trimethylamine oxide reduction by Salmonella. Canadian Journal of Microbiology 20, 1745-1748.

Kline, E. S. \& MAHLER, H. R. (1965). The lactic dehydrogenases of E. coli. Annals of the New York Academy of Sciences 119, 905-919.

LEHNINGER, A. L. (1970). Biochemistry. New York: Worth.

Madigan, M. T. \& Gest, H. (1978). Growth of a photosynthetic bacterium anaerobically in darkness, supported by 'oxidant-dependent' sugar fermentation. Archives of Microbiology 117, $119-122$.

N. N. (1956). Directions for use of 3599-x van Slyke-Folch Manometric Apparatus. Philadelphia: Arthur H. Thomas Co.

NeTTER, H. (1969). Theoretical Biochemistry. Edinburgh: Oliver \& Boyd.
Neujahr, H. Y. \& Ewaldson, B. (1964). Counting of weak $\beta$-emitters in bacterial cells by means of the liquid scintillation method. Analytical Biochemistry 8, 487-494.

SAKaguchI, M. \& KaWAI, A. (1977). Electron donors and carriers for the reduction of trimethylamine $N$-oxide in Escherichia coli. Bulletin of the Japanese Society of Scientific Fisheries 43, 437-442.

Stouthamer, A. H. (1969). Determination and significance of molar growth yields. Methods in Microbiology 1, 629-663.

Stouthamer, A. H. (1977). Energetic aspects of the growth of micro-organisms. Symposia of the Society for General Microbiology 27, 285-315.

Stouthamer, A. H. \& Bettenhausen, C. (1972). Influence of hydrogen acceptors on growth and energy production of Proteus mirabilis. Antonie van Leeuwenhoek 38, 81-90.

STRøM, A. R. (1971). Bakterielle omsetninger $i$ anaerobt silde-ekstrakt. Lic. techn. thesis, Norwegian Institute of Technology, University of Trondheim, Norway.

StRøM, A. R. \& LARSEN, H. (1979). Anaerobic fish spoilage by bacteria. Biochemical changes in herring extracts. Journal of Applied Bacteriology 46, 269-277.

TARR, H. L. A. (1954). Microbiological deterioration of fish post mortem, its detection and control. Bacteriological Reviews 18, 1-15.

Unemoto, T., Hayashi, M., YokoI, N. \& MiYakI, K. (1964). Studies on trimethylamine- $N$-oxide reductase in bacteria. Annual Report from the Institute of Food Microbiology (Chiba University) 17, 15-21.

Unemoto, T., Hayashi, M., Miyaki, K. \& Hayashi, M. (1965). Intracellular localization and properties of trimethylamine- $N$-oxide reductase in Vibrio parahaemolyticus. Biochimica et biophysica acta 110, 319-328.

Watson, D. W. (1939a). Studies of fish spoilage. IV. The bacterial reduction of trimethylamine oxide. Journal of the Fisheries Research Bourd of Canada 4, 252-266.

Watson, D. W. (1939b). Studies of fish spoilage. V. The role of trimethylamine oxide in the respiration of Achromobacter. Journal of the Fisheries Research Board of Canada 4, 267-280.

Wood, W. A. (1961). Fermentation of carbohydrates and related compounds. In The Bacteria, vol. 2, pp. 59-149. Edited by I. C. Gunsalus \& R. Y. Stanier. New York \& London: Academic Press.

Wood, H. G. \& Gest, H. (1957). Determination of formate. Methods in Enzymology 3, 285-292.

YAMADA, K. (1967). Occurrence and origin of trimethylamine oxide in fishes and marine invertebrates. Bulletin of the Japanese Society of Scientific Fisheries 33, 591-603.

YAMAMOTO, I. \& IsHimoto, M. (1977). Anaerobic growth of Escherichia coli on formate by reduction of nitrate, fumarate, and trimethylamine $N$-oxide. Zeitschrift für allgemeine Mikrobiologie 17, 235242. 